\title{
Current Approaches and New Developments in the Pharmacological Management of Tourette Syndrome
}

\author{
Julio Quezada ${ }^{1} \cdot$ Keith A. Coffman ${ }^{2}$
}

Published online: 15 January 2018

(C) The Author(s) 2018. This article is an open access publication

\begin{abstract}
Tourette syndrome (TS) is a neurodevelopmental disorder of unknown etiology characterized by spontaneous, involuntary movements and vocalizations called tics. Once thought to be rare, TS affects $0.3-1 \%$ of the population. Tics can cause physical discomfort, emotional distress, social difficulties, and can interfere with education and desired activities. The pharmacologic treatment of TS is particularly challenging, as currently the genetics, neurophysiology, and neuropathology of this disorder are still largely unknown. However, clinical experience gained from treating TS has helped us better understand its pathogenesis and, as a result, derive treatment options. The strongest data exist for the antipsychotic agents, both typical and atypical, although their use is often limited in children and adolescents due to their side-effect profiles. There are agents in a variety of other pharmacologic categories that have evidence for the treatment of TS and whose side-effect profiles are more tolerable than the antipsychotics; these include clonidine, guanfacine, baclofen, topiramate, botulinum toxin A, tetrabenazine, and deutetrabenazine. A number of new agents are being developed and tested as potential treatments for TS. These include valbenazine, delta-9-tetrahydrocannabidiol, and ecopipam. Additionally, there are agents with insufficient data for efficacy, as well as agents that have been shown to be ineffective.
\end{abstract}

Keith A. Coffman

kacoffman@cmh.edu

Julio Quezada

jfquezada@cmh.edu

1 Child Neurology Resident, Children's Mercy Hospital, Kansas City, MO, USA

2 Division of Neurology, Movement Disorders Clinic, Tourette Syndrome Center of Excellence, Children's Mercy Hospital, Professional Office Building, Office 1M02.35, 2240 Kenwood Avenue, Kansas City, MO 64108, USA
Those without sufficient data for efficacy include clonazepam, ningdong granule, 5-ling granule, omega-3 fatty acids, and $\mathrm{n}$-acetylcysteine. The agents that have been shown to be ineffective include pramipexole and metoclopramide. We will review all of the established pharmacologic treatments, and discuss those presently in development.

\section{Key Points}

While most of the data for treatment of Tourette syndrome (TS) indicate that antipsychotic medications, both typical and atypical, are most effective, other medications (e.g., clonidine, guanfacine, topiramate, baclofen, botulinum toxin A, and tetrabenazine) are typically used first to avoid the potential side effects of dopamine blockade.

Presently, there is no medication that has proven efficacy for all individuals with TS. This is likely due to the phenotypic variability of individuals with TS.

There are promising medications in development for the treatment of TS that offer different mechanisms of action from antipsychotic medications, but the data to support their use are preliminary. Specifically, there are preliminary data for two new vesicular monoamine transporter-2 (VMAT2) inhibitors (deutetrabenazine and valbenazine), cannabinoids, and ecopipam (a novel D1 receptor antagonist).

There are also some preliminary data indicating possible effectiveness of some complementary and alternative medicine preparations for the treatment of TS; specifically, omega- 3 fatty acids, $\mathrm{n}$-acetylcysteine, ningdong granule, and 5-ling granule. 


\section{Introduction}

Tourette syndrome (TS) is a neurodevelopmental movement disorder typically associated with comorbid psychiatric conditions (attention deficit disorder [ADHD], obsessive compulsive disorder [OCD], anxiety, and depression), characterized by the presence of motor and vocal tics. The epidemiology of tics and TS has been evaluated by several studies in the past. In 2012, Knight et al. performed a systematic review and meta-analysis of the prevalence, incidence, and epidemiology of tics and TS. They reported an overall prevalence of TS in children of $0.77 \%$, alpha: $95 \%$ CI $0.39-1.51$, which translates to 7.7 per 1000 school-aged children [1].

TS is characterized by the presence of tics, which are "sudden, rapid, arrhythmic, recurrent and involuntary movements and/or sounds that are indistinguishable from spontaneous movements but occur misplaced in context and time" [2]. Tics are also commonly preceded by a premonitory sensation followed by a sensation of relief after the tic is performed. The actual tic itself, though, is under conscious control. This, then, changes tics from involuntary to semi-involuntary movements or sounds. It is worth noting though that conscious tic suppression often leads to an increase in inner tension and discomfort [3]. Though tics are the sine qua non finding in TS, they are not exclusive to this condition and may be seen in other medical conditions (e.g., Huntington disease, viral encephalitis, substance abuse). In fact, the Diagnostic and Statistical Manual of Mental Disorders (DSM), fifth edition, lists six different tic disorders [4].

The DSM V has specific criteria listed to diagnose TS; these include presence of tics before the age of 18 years. The tics must be present for at least 1 year and include at least two motor tics and one phonic tic throughout the course of the disease. The different tics do not need to present concurrently, but should have been present at some point throughout the illness course [4].

Tics initially present between the ages of 4 and 8 years. Their frequency and severity tends to increase and become worse between the ages of 8 and 12 years, followed by a gradual decrease. According to the European clinical guidelines for Tourette syndrome and other tic disorders, $80 \%$ of patients who present with tics under the age of 10 years will experience a significant decrease in tic frequency and severity during adolescence and by age 18 years will no longer experience any impairment from tics [2]. The remaining $20 \%$ of patients do not experience a decrease in tics and some of these patients might also go on to develop the most severe and debilitating forms of tics [2].

It is difficult to establish a standardized treatment model for tics. This is due to the spontaneous variations of tics in an individual over time and the variable impact a tic can have on different individuals and their families. The presence of co-morbidities that are usually present with TS and their variable severity is another challenging feature in the treatment of tics. The current options for treatment of tics and TS include behavioral interventions, pharmacological interventions, and surgical interventions, with the latter reserved for the most severe and debilitating cases. The following article will focus on reviewing current pharmacological treatment options available for management of tics and TS. There is compelling evidence to indicate that non-pharmacologic therapy, specifically comprehensive behavioral intervention for tic (CBIT), is highly effective for the treatment of TS [5] and should be considered as the first therapeutic option for patients with TS [6]. A critical first step in the treatment of TS is "proper education of the patients, family members, teachers, and other individuals who interact with the patient about the broad range of clinical features and variable course of the disorder" [7]. If CBIT is not appropriate, is ineffective, or is unavailable, pharmacotherapy should be considered. This manuscript offers a comprehensive review of the available evidence to recommend different medications and a treatment algorithm to help choose the medication best suited for each patient based on available medical evidence. The algorithm is included in pictorial form as Fig. 1.

We searched PubMed using the keywords 'Tourette syndrome' or 'tic disorder', 'treatment', 'pharmacological treatment', 'medication treatment', in humans without any date or language limits applied to the search. This search yielded 229 results. Single case reports were then excluded. Only references that discussed the treatment of TS were further analyzed and used for the creation of this review. Specific additional searches were performed for treatments that were recommended upon initial peer review of this manuscript. Additionally, established treatment guidelines for the pharmacologic treatment of TS from Canada and Europe were included in our analysis of evidence for efficacy as there are no established treatment guidelines from the United States.

\section{Indications for Pharmacological Treatment}

It is generally accepted that transient tic disorders do not cause significant impairment in day-to-day activities and therefore do not require any pharmacological intervention routinely. With regards to TS, however, it has been demonstrated that scores for validated quality of life (QoL) measures are low for these patients. It seems, though, that the lower scores attained are not related to tics themselves, but more so to the co-morbidities associated with TS and 


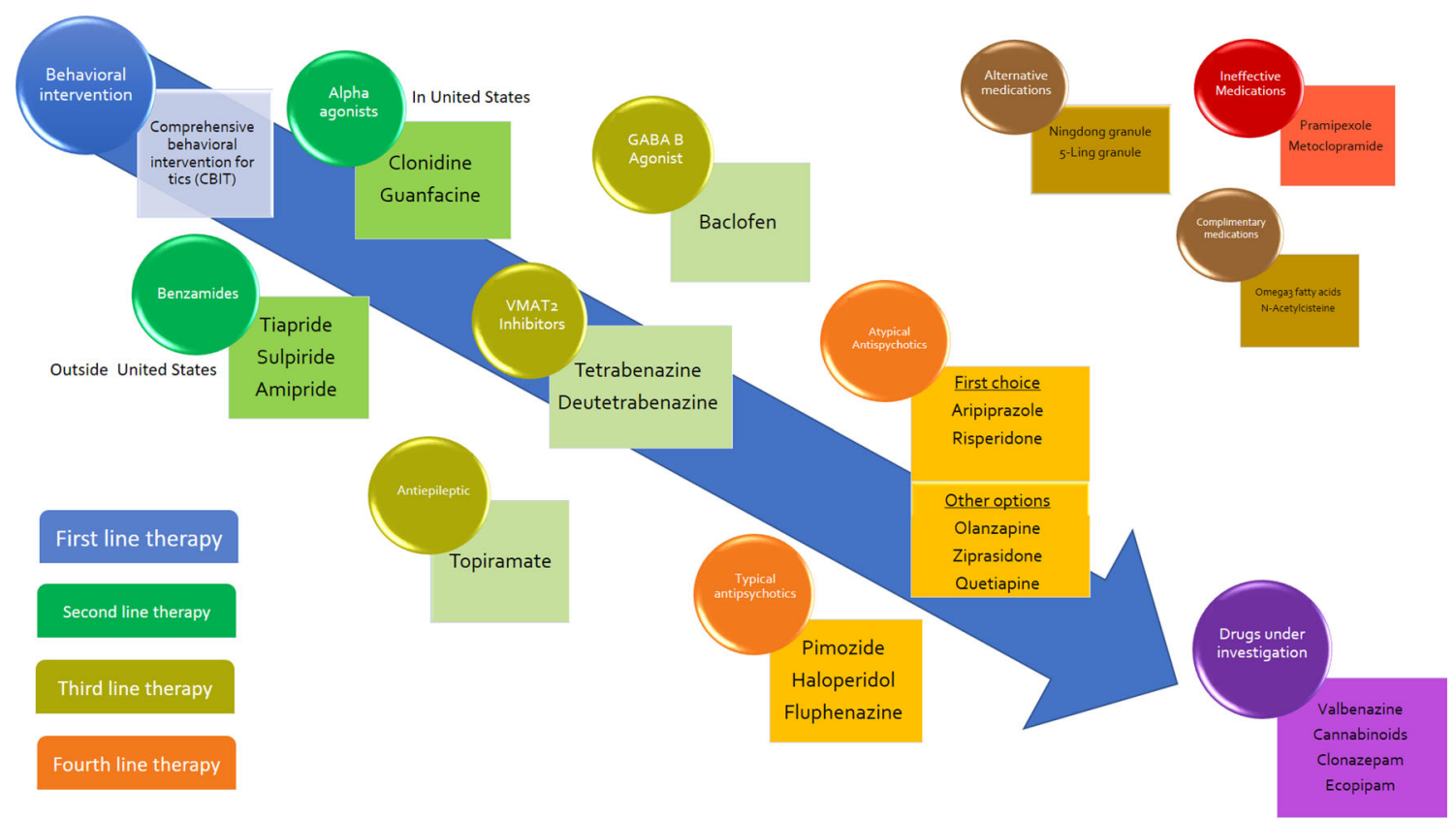

Fig. 1 Tourette syndrome treatment algorithm. Therapies follow a progression that starts with the intervention that has no side effects and concludes with the medications that can have the most severe side effects. Medication selection should follow this progression. Note that there is more than one medication category in each progressive line of therapy, so more than one option is available in each tier. Complimentary medications are available and have evidence for

peer victimization (teasing by other children because of tics) [8]. Treatment for tics is therefore only required when the tics themselves are causing social problems (e.g., bullying), emotional problems (e.g., low self-esteem, depression, anxiety), discomfort (e.g., physical pain or injuries) or impair performance (e.g., academic or sleep disruption) [9].

Behavioral interventions should be recommended as an initial intervention. They are highly effective as demonstrated by the landmark placebo-controlled trial in 2010 by Piacentini et al. and are free from pharmacologic side effects [5]. If these interventions are not successful or not feasible (e.g., lack of coverage by insurance, lack of certified therapists, unwillingness of patient to participate), pharmacologic interventions can be pursued. When initiating a medication for treatment of tics, it is important to bear in mind that these interventions may not completely eliminate tics. On average, medications for tics can reduce symptoms by about $25-50 \%$ [9]. This information should be communicated with the patient and family members to avoid disappointment and frustration. In clinical practice, some patients may achieve complete or near complete control of tics with medication therapy; however, this should not be put forth as the expectation when initiating pharmacotherapy. their use as an add-on therapy and not as single agents. Alternative medications are available and have some evidence for their efficacy, but are not widely used and cannot yet be recommended. Drugs under investigation show promise in the treatment of tics, but still need further studies before their use can be recommended. VMAT2 vesicular monoamine transporter-2

\section{Agents with Evidence of Efficacy}

We will now discuss a variety of agents for which there is sufficient evidence for efficacy in the treatment of TS. These agents are presented in three categories: nondopaminergic agents, agents that act through blockade of dopamine receptors, and agents that are vesicular monoamine transporter-2 (VMAT2) inhibitors.

\subsection{Non-dopaminergic Agents}

There is evidence suggesting, based on the observation of tic improvement with the use of dopaminergic blocking agents, that abnormal dopaminergic signaling is involved in the pathophysiology of tics. Abnormal dopaminergic signaling does not, however, explain the close association of TS with ADHD and OCD and other psychiatric comorbidities like anxiety, depression, and oppositional defiant disorder. Noradrenergic and serotoninergic systems appear to be involved in the pathophysiology of TS, yet their exact role is still unclear [10]. The successful use of non-dopaminergic medications for tic management along with management of comorbidities in TS further supports this notion. 


\subsubsection{Alpha-2 Agonists}

3.1.1.1 Clonidine Clonidine has been used for TS for over 30 years. It is an $\alpha-2$ adrenergic receptor agonist. Case reports of its efficacy first appeared in the 1980s and initial open-label trial evidence was contradictory. The controversy was deepened by randomized trials that showed minimal to no improvement of tics with clonidine [11]. The controversy was laid to rest after a large randomized control trial (RCT) was conducted in 2002 by the Tourette Study Group. The trial included 136 children with TS and ADHD who were randomized to receive clonidine alone or methylphenidate alone or clonidine + methylphenidate or placebo. In this study, tic severity improved the most in the clonidine + methylphenidate group followed by the clonidine alone group and least improvement was seen in the methylphenidate alone group followed by the placebo group [12]. Another benefit of clonidine is its availability as an oral preparation as well as a transdermal preparation. A 2008 double-blind, placebo-controlled multicenter trial of 437 patients using a clonidine adhesive patch versus placebo revealed a significant improvement in the randomly assigned clonidine group compared with the clinical control group [13]. Side effects commonly seen with clonidine include sedation, bradycardia, orthostatic hypotension, and dry mouth, as well as localized skin irritation with the clonidine patch. Thanks to the preferable side-effect profile and moderate quality of evidence of tic reduction with clonidine, this medication was given a strong recommendation by the Canadian guidelines for evidence-based treatment of tic disorders with its use applicable to most patients without reservations by the physician [14]. Recommended starting dose is $0.05 \mathrm{mg}$ per day and titrate up slowly with a close monitoring of blood pressure and heart rate to a therapeutic range of $0.1-0.3 \mathrm{mg}$ per day in adults and children, divided 3-4 times per day $[11,14]$.

3.1.1.2 Guanfacine Guanfacine is another $\alpha$-2 adrenergic receptor agonist that has a moderate effect in tic reduction and improving attention. The evidence in favor of use of guanfacine for tic reduction comes from two open-label studies [15, 16] and three RCTs [17-19]. Both of the openlabel studies showed an improvement in tic severity with the use of guanfacine $[15,16]$. All three RCTs compared guanfacine with placebo. The first RCT evaluated 34 children with TS and ADHD who were randomized to either receive guanfacine or placebo over an 8-week period. At the end of this period, patients on guanfacine had a statistically significant reduction in their Yale Global Tic Severity Scale (YGTSS). The patients in the placebo group had no change in their score. The patients receiving guanfacine also had an improvement in their ADHD symptoms [17]. The second RCT was of poor quality and failed to show a difference between guanfacine and placebo [18]. The third RCT compared extended-release guanfacine with placebo. Despite a reduction in the YGTSS, it failed to show a clinically meaningful effect size for tic reduction with the use of the extended-release formulation (YGTSS total score declined from $26.25 \pm 6.61$ to $23.56 \pm 6.42, p=0.08)[t(15)=1.84$; $p=0.08$; effect size $=0.35$ ] [19]. The main side effects of guanfacine include fatigue, insomnia, irritability, lightheadedness, stomachache, and sleep disturbance. Like clonidine, guanfacine had a strong recommendation with a moderate level of evidence by the Canadian guidelines for evidence-based treatment of tic disorders [14]. Dosing is recommended to start at $0.5 \mathrm{mg}$ per day and titrate to up to $4 \mathrm{mg}$ per day $[11,14]$.

\subsubsection{Baclofen}

Baclofen is a GABAB receptor agonist that is commonly used for the treatment of spasticity. The GABAergic properties of baclofen were suggested to be helpful in tic management after an open-label trial in 1999. A total of 264 patients aged 6-18 years were treated with an initial dose of $10 \mathrm{mg}$ per day with subsequent dose increases of $10 \mathrm{mg} /$ week until desired tic suppression was achieved or the patient developed side effects. The dose ranged $10-80 \mathrm{mg} /$ day (mean $30 \mathrm{mg} /$ day) for 4 weeks. Statistically significant decreases were noted in motor and vocal $(p<0.02)$ tics as measured by the YGTSS, although further data were not provided. Six patients experienced sedation and drowsiness [20]. This trial, along with an RCT [21] of 10 children 8-14 years old randomized to either baclofen or placebo that demonstrated a decrease in the YGTSS that was not statistically significant, was included in the Canadian guidelines for evidence-based treatment of tic disorders. The recommendation was weak due to low quality of evidence [14].

\subsubsection{Topiramate}

Topiramate is a broad-spectrum anticonvulsant that is GABAergic, and blocks AMPA ( $\alpha$-amino-3-hydroxy-5methylisoxazole-4-propionic acid)/kainate receptors. To date, there is only one randomized, double-blind, placebocontrolled trial of topiramate for the treatment of TS. This 10-week study of 29 subjects (pediatric and adult) demonstrated a statistically significant reduction in YGTSS total tic score [22]. Dose range was $25-200 \mathrm{mg} /$ day. The main side effects were headache and diarrhea. 


\subsubsection{Botulinum Toxin A}

Botulinum toxin (Botox) is a neurotoxic protein that inhibits acetylcholine release at the neuromuscular junction. It is Food and Drug Administration (FDA) approved for the treatment of migraine headache, blepharospasm, cervical dystonia, and spasticity [23]. There is one randomized, placebo-controlled trial for Botox in the treatment of TS. It was a small study of only 20 patients, but it did demonstrate statistically significant reduction in tics [24]. Patients did not feel that they had improvement, despite the results. Weakness, not surprisingly, was the main side effect, and no dosing guidelines were provided.

\subsection{Dopaminergic Blockade}

Dopamine blockade was demonstrated to be beneficial for tic reduction in 1973 with the use of haloperidol (Haldol) [10]. The hallmark clinical finding in TS is tics, which have led some to classify it as a movement disorder, different from hyperkinetic movement disorders [2]. This classification may lead one to believe that the pathological findings in TS should reside within the basal ganglia. Tics, however, wax and wane, are influenced by a patient's emotional state, and can be temporarily suppressed [2]. These findings suggest that tics are not solely based on basal ganglia pathology and likely involve the limbic system as well. Another interesting finding in tic disorders is that the tics temporarily remit during periods of intense attention, like playing an instrument or performing a task [6]. These high-attention scenarios require engagement of the cerebral cortex, which therefore implies that the cerebral cortex is also involved in the genesis of tics. The circuitry that involves these structures (cortex, basal ganglia, and thalamus) has been termed the cortico-striatothalamo-cortico circuit (CSTC). "Three CSTC circuits are potentially involved in GTS: the habitual behavioural circuit (the premotor cortex-putamen circuit), the goal-directed circuit (the ventral medial prefrontal cortex-caudate nucleus circuit) and the emotion-related limbic circuit (inputs from the hippocampus, amygdala, prefrontal cortex and anterior cingulate gyrus to the ventral striatum)" [6]. Dopamine blocking agents have been postulated to help control tics by blocking abnormal dopaminergic systems within the aforementioned circuits. The beneficial effects of dopamine, specifically D2 receptor, blockade have been reported to provide up to $70 \%$ tic reduction, although it is achieved at the cost of side effects derived from this mechanism-medication-induced dyskinesias [25]. Other important side effects may result from hyperprolactinemia (galactorrhea, gynecomastia, irregular menses, and sexual dysfunction) and alterations in cholinergic, serotonergic, histaminergic, and alpha-adrenergic transmission, and thereby might lead to weight gain, drowsiness, and excessive sedation $[9,11]$.

\subsubsection{Typical Antipsychotics}

3.2.1.1 Pimozide Pimozide is a dopamine receptor blocker, but also acts as a calcium channel blocker. It causes fewer medication-induced dyskinesias than haloperidol, and also exhibits less sedative effects $[11,26]$. A Cochrane review from 2009 evaluated six RCTs comparing pimozide with placebo alone, haloperidol alone, placebo and haloperidol, and risperidone in the treatment of tics. Pimozide was superior to placebo in three RCTs. Compared with haloperidol, pimozide showed similar efficacy in two RCTs and was inferior in one RCT. No significant differences between pimozide and risperidone were detected [27]. Pimozide has been associated with cardiac arrhythmias and prolongation of QTc interval. A 2011 study compared the cardiovascular safety profile of pimozide with that of aripiprazole and found that patients taking pimozide developed lower blood pressure and a prolongation of QTc interval, while patients on aripiprazole showed an elevation in blood pressure and no changes in QTc interval [28]. Pimozide is used at doses of 2-8 $\mathrm{mg}$ per day given once daily, with a maximum of $10 \mathrm{mg} /$ day [26]. Children $\geq 2$ years and adolescents initially receive $0.05 \mathrm{mg} / \mathrm{kg} / \mathrm{dose}$ once daily, preferably at bedtime; dose may be increased every third day if needed; maximum daily dose is $0.2 \mathrm{mg} / \mathrm{kg} /$ day, not to exceed $10 \mathrm{mg} /$ day [29]. Pimozide was approved by the FDA for use in patients with TS in 1984 [30].

\subsubsection{Haloperidol Haloperidol was the first medication} shown to be effective for tic management. Its potential beneficial effects were first reported in a case report in a patient who had undergone a frontal lobectomy and experienced a reduction of tics with use of haloperidol [31]. Haloperidol has been shown to be effective when compared with other typical neuroleptics and in placebo-controlled trials [29, 32-35]. It has been estimated that haloperidol might achieve up to $91 \%$ tic reduction at maximum dose [28]. These benefits are offset by the higher incidence of adverse effects when compared with other typical neuroleptics. Significantly, a 24-week, doubleblind, placebo-controlled, randomized, cross-over study found that haloperidol did not have a significant effect on tics, but did have a 3-fold increased risk of side effects compared with pimozide [29]. Haloperidol is usually started at $0.5 \mathrm{mg} /$ day and carefully titrated upwards in 0.25 - to $0.5-\mathrm{mg}$ increments every 5-7 days until optimal tic control is achieved. The typical dose range for treatment of tics with haloperidol is $2-10 \mathrm{mg}$ daily, although doses up to $20 \mathrm{mg}$ daily have been studied [33]. Due to its higher 
risk of side effects, haloperidol should only be used in severely disabled patients who have failed other medications [29]. Haloperidol was the first medication approved by the FDA for the treatment of adult patients with TS in 1969 and for children in 1978 [30].

\subsubsection{Fluphenazine Fluphenazine is one of the oldest} typical antipsychotics that acts by blocking both D1 and D2 receptors [26]. A retrospective chart review from 2014 evaluated the treatment response of 268 patients over a 26-year period. Patients were started at an average age of 15.8 years and received the medication for an average of 2.6 years. Results showed that of the 268 patients, 211 $(80.5 \%)$ had a moderate improvement of tics. The most common side effects included drowsiness, fatigue, or both, observed in $70(26.1 \%)$ patients. There were no cases of tardive dyskinesia (TD) [36]. An older placebo-controlled, double-blind trial reportedly showed fluphenazine and trifluoperazine to be as effective as haloperidol but with fewer side effects when used for tic suppression, mainly TD [37]. Fluphenazine should be considered for treating moderate to severe tics that are refractory to preferred treatments. Fluphenazine is started at $0.5-1.0 \mathrm{mg}$ daily and slowly increased by $0.5-$ to $1.0-\mathrm{mg}$ increments every 5-7 days to approximately $3 \mathrm{mg}$ per day in children and up to $10 \mathrm{mg}$ per day in adults $[14,26]$.

\subsubsection{Atypical Antipsychotics}

Ten atypical antipsychotics are currently approved by the FDA in the USA: risperidone, olanzapine, ziprasidone, quetiapine, aripiprazole, asenapine, iloperidone, lurasidone, paliperidone, and clozapine. These medications were developed in an effort to decrease the likelihood of medication-induced dyskinesias, while also providing a means to control psychosis. Their safer side-effect profile, with regards to medication-induced dyskinesia, has sparked the use of atypical antipsychotics for other indications that are not yet FDA approved, like mood disorders, other psychoses, autism spectrum disorder and tics [26].

Atypical antipsychotics are not without risk. Their sideeffect profile does include an increased risk of developing metabolic abnormalities, type 2 diabetes mellitus, cardiovascular disease, weight gain, and endocrine abnormalities like hyperprolactinemia. Patients on atypical antipsychotics should undergo routine measurement of weight, BMI, waist circumference, blood pressure, liver function tests, fasting serum lipids, and glucose [26].

The European Society for the Study of Tourette Syndrome (ESSTS) distributed an online survey to 57 of its active members in 18 different countries in 2012 in order to determine their prescribing practices. They obtained a response from 44 clinicians that showed that risperidone was the most commonly prescribed drug for treatment of tics [38].

3.2.2.1 Aripiprazole Aripiprazole is a partial D2, D3, and D4 receptor agonist, as well as a partial 5-HT1A and 5-HT2C receptor agonist. As a partial D2 receptor agonist, it results in an overall decrease in D2 stimulation. It has moderate affinity for histamine and alpha-adrenergic receptors [26]. There are multiple placebo-controlled randomized trials supporting the use of aripiprazole for TS. The first, published in 2013, was a 10-week trial of children and adolescents and contained 61 subjects. It demonstrated significant reduction in the mean total tic score on the YGTSS of 15 compared with 9.6 for the placebo group $(p=0.0196)$ [39]. The most recent was an 8-week study published in 2017. This large study, which enrolled 133 children and adolescents, demonstrated significant reduction in tics on the YGTSS and critically demonstrated that more than $65 \%$ of patients in the treatment groups had 'very much improved' or 'much improved' scores on the Clinical Global Impression-Tourette's Syndrome scale [40]. Common side effects between these two studies were sedation, somnolence, and weight gain [38, 39]. The Canadian guidelines for the treatment of TS gave aripiprazole a weak recommendation due to the quality of data; however, this recommendation predates the two large placebo-controlled trials discussed above [14]. Aripiprazole was FDA approved for the treatment of TS in 2014 [41]. Recommended initial dose is $2 \mathrm{mg}$ per day with a maximum of 10 or $20 \mathrm{mg}$ a day, depending on weight.

3.2.2.2 Risperidone Risperidone is the best examined atypical antipsychotic for treatment of TS. Risperidone is a 5-HT2 receptor antagonist at low doses and functions as a D2 antagonist at high doses. It also has moderate to high affinity for $\alpha-2, D 3$, D4, and H1 receptors [26]. It has been demonstrated to have similar or even better efficacy for tic management when compared with pimozide [42, 43]. There are a total of five randomized, double-blind, control trials that have demonstrated efficacy of risperidone for the treatment of tics [42-46], yet the long-term side effects (of which hyperprolactinemia due to tubero-infundibular D2 antagonism is the most impactful) may be significant $[9,47]$. In fact, the Canadian Guidelines for the EvidenceBased Treatment of Tic Disorders gave risperidone a weak recommendation for tics in TS due to its risk-benefit profile as it requires monitoring of medication-induced dyskinesias and metabolic side effects [14]. Due to its diverse effects on neurotransmission, risperidone may be useful for treating co-morbid symptoms such as aggression or obsessive-compulsive symptoms in children with TS, though more evidence for treating psychiatric comorbidities in TS with risperidone is needed [26]. Doses are 
initiated at $0.25 \mathrm{mg}$ daily and increased every 5-7 days as indicated to approximately $0.25-4.0 \mathrm{mg}$ daily $[11,14]$.

\subsubsection{Olanzapine Olanzapine is characterized by its} high-affinity antagonism of D1, D2, D3, D4, 5-HT2A, 5-HT2C, H1, and muscarinic receptors [9]. The use of olanzapine in TS is supported by three open-label studies, one non-randomized, single-blind study with a 2 -week placebo run-in, and one non-randomized crossover study comparing olanzapine with pimozide [48-52]. All of these studies reported a decrease in tic severity with use of olanzapine. While all three open-label studies reported a decrease in tic severity and improvement in the YGTSS, they all reported significant side effects due to sedation, weight gain, and increased appetite [48, 50, 52].

Compared with other atypical antipsychotics, olanzapine has greater 5HT2C than D2 antagonism, which may explain the lower incidence of medication-induced dyskinesias [11]. Additionally, olanzapine does not appear to block dopamine within the tubero-infundibular tract, explaining the lower incidence of hyperprolactinemia than with typical antipsychotic agents or risperidone [11]. Nevertheless, the metabolic side effects seen with olanzapine may limit its use [26]. Olanzapine causes the most weight gain among second-generation antipsychotics, and has been associated with increases in BMI and waist circumference, lipids, liver enzymes, and blood sugar [11]. Olanzapine is started at $2.5-5.0 \mathrm{mg}$ daily and increased every 5-7 days up to a maximum of $20 \mathrm{mg}$ daily [11].

3.2.2.4 Ziprasidone There is minimal evidence to support the use of ziprasidone in TS. Its efficacy for reduction of tics has been demonstrated in one randomized, doubleblind, placebo-controlled study in 28 children and adolescents [53] and one open-label study in 24 children and adolescents [54]. It has low affinity for D2 receptors, high affinity for 5HT2A, 5HT1A, and 5HT2C receptors, and moderate affinity for $\mathrm{M} 1$ and $\mathrm{H} 1$ receptors. The use of ziprasidone requires monitoring for medication-induced dyskinesias and EKG for prolongation of QTc [14]. Unlike other atypical antipsychotics, it does not seem to cause significant weight gain. Side effects include somnolence, sedation, and akathisia. Ziprasidone is started at $5-10 \mathrm{mg}$ daily and gradually increased every week to $10-40 \mathrm{mg}$ daily [14].

3.2.2.5 Quetiapine Quetiapine has moderate affinity for 5-HT1A, 5-HT2, D1, D2, and H1 receptors and has low affinity for $\alpha-1$ and $\alpha-2$ adrenergic receptors. The evidence for the use of quetiapine for tics in TS comes from two open-label studies. One study involved 12 adults and did not show a statistically significant reduction in tics after 12 weeks of treatment with a mean dose of $205.8 \mathrm{mg} / \mathrm{day}$
[55]. The other was an 8 -week trial on 12 subjects with a mean age of $11.4 \pm 2.4$ years. At the end of the 8-week period, subjects had a statistically significant reduction in the YGTSS [56]. Sedation and weight gain are the most common reported side effects. Quetiapine can be initiated at $12.5-25.0 \mathrm{mg}$ daily and increased as tolerated and indicated up to $300-400 \mathrm{mg}$ daily [26].

3.2.2.6 Benzamides This class of drugs includes tiapride, sulpiride, and amisulpride. In the German-speaking world, benzamides such as tiapride and sulpiride are commonly used as first-line agents to treat TS, particularly in children and adolescents. None of these agents are available in the US [11]. They are specific D2-blocking agents, yet in contrast to the typical antipsychotics, they have little to no antipsychotic effect.

Tiapride has been used for management of tics since 1970. It not only blocks the supersensitive D2 receptor in the striatum, but it is also assumed that it has some 5HT3 and 5HT4 blocking capabilities [11]. The main adverse reactions include drowsiness, transient hyperprolactinemia, and weight gain [11]. In a double-blind, randomized, placebo-control, crossover study for tiapride, no adverse reactions on the patient's cognitive performance were reported and the study found "good clinical antidyskinetic properties" [57].

The positive effects of sulpiride on tic management have also been reported on since 1970 [11]. In addition to these effects, it has also been shown to have mild antipsychotic, antidepressive, and anxiolytic effects [11]. Sulpiride is a highly selective D2 receptor blocker with fewer medication-induced dyskinesias and vegetative side effects than haloperidol. An open-label study in 2009 evaluated 189 children, with an average age of 8 years, after 6 weeks of sulpiride treatment for tics. There was reported improvement of vocal and motor tics on this medication, with sedation being reported as a side effect in $16.4 \%$ of participants [58]. Successful treatment of tics with amisulpiride has only been published in case reports [11].

\subsection{Vesicular Monoamine Transporter-2 Inhibitors}

The VMAT2 transports dopamine, norepinephrine, and serotonin from synaptic vesicles to the synapse [59]. There are currently three VMAT2 inhibitors with evidence for, or studies being developed for, the treatment of TS (tetrabenazine, deutetrabenazine, valbenazine).

\subsubsection{Tetrabenazine}

Tetrabenazine is currently FDA approved for the treatment of the chorea in Huntington disease. By inhibiting VMAT2, it prevents translocation of neurotransmitter monoamines 
from the cytoplasm into synaptic vesicles. The data for the use of tetrabenazine comes a from long-term, open-label study by Jankovic et al. [60]. In this study of 10 individuals with TS, who were treated for an average of 9.4 months, four had marked improvement in tic control, and three had mild improvement. All responders were children or teens. Drowsiness was the most common side effect. There was also a long-term, open-label prospective analysis of 120 subjects, both pediatric and adult, which demonstrated that $76 \%$ "improved on the clinical global impression of change (CGI-C)". Unfortunately, 93\% of the subjects in this study were on other medications at the time [61]. To date, there has not been a randomized placebo-controlled trial of tetrabenazine [59]. The Canadian guidelines for the treatment of TS give it a weak recommendation for "very low-quality data" [14]. No clear dosing guidelines are available.

\subsubsection{Deutetrabenazine}

Deutetrabenazine is an isotopic isomer of tetrabenazine resulting from the replacement of the two methoxy groups (-OCH3) with two trideuteromethoxy groups (-OCD3) installed at the 9 and 10 positions. This increases the halflife and reduces side effects. Deutetrabenazine has recently been FDA approved for the chorea from Huntington disease as well as tardive dyskinesia [62]. This medication has been studied in a 6-week, open-label trial of 12- to 18-year-old patients with TS. There was a reduction in the mean YGTSS score of 11.2 on doses of 18-36 mg a day [61]. Side effects were fatigue, headache, and irritability. No placebo-controlled studies have been completed to date.

\section{Agents Without Sufficient Evidence of Efficacy}

\subsection{Valbenazine}

Valbenazine is a VMAT2 inhibitor, FDA approved for the treatment of tardive dyskinesia, that is presently being studied for the treatment of TS [63]. There are presently three phase II trials of TS ongoing in the US. At time of publication, none of these studies have published results. Side effects have been sedation, anticholinergic effects, and balance disorders.

\subsection{Cannabinoids}

\subsubsection{Delta-9-tetrahydrocannabinol}

Derivatives of the Cannabis sativa plant have recently received extensive popular press and attention in the US for the treatment of a myriad of neurologic disorders. Delta-9tetrahydrocannabinol (THC) acts as an agonist of the cannabinoid receptor. There are placebo-controlled, randomized trials for the treatment of TS. The first was a 2-day, single-dose trial with a 4-week washout. There were statistically significant reductions in both tics and OCD behaviors [64]. The second trial was a sustained treatment trial, 6 weeks in duration, of 24 subjects, with an escalating dose schedule. It did demonstrate significant reduction in tics, without significant side effects [65]. In both studies, dronabinol was used and dosing was 5-10 mg a day. Curtis et al., in a Cochrane Review article, concluded that currently there is not significant data to determine if it is effective at this point for TS [66].

\subsection{Clonazepam}

Clonazepam is a benzodiazepine that has a long history in the treatment of TS [67], yet no placebo-control trials have been done [11]. There have been two single-blind comparison studies of clonazepam. The first study showed that clonazepam was superior to clonidine for tic suppression [68], and the second study, conducted by Merikangas et al., showed that patients with a high red blood cell to plasma choline ratio responded better to clonazepam than to haloperidol [69]. This is critical based on a prior observation of elevated red blood cell choline levels in patients with TS [70]. There are no data on other benzodiazepines except a case report about the therapeutic effect of lowdosage diazepam on facial tics in children [71]. As with all benzodiazepines, the use of clonazepam is limited by tolerance and adverse reactions including sedation, short-term memory problems, ataxia, and paradoxical disinhibition [11].

\subsection{Dopamine D1 Receptor Antagonist}

Ecopipam is a selective D1/D5 antagonist that is being studied for TS. Presently, there is one open-label, 8-week study of 18 adults with TS. Subjects had a 5.2 decrease in YGTSS total score during treatment. The main side effects seen were sedation, fatigue, and insomnia [72]. There are preliminary results available for the ongoing multicenter, double-blind, placebo-controlled crossover trial of ecopipam in children and adolescents that were presented in a poster at the 2017 Movement Disorders Society meeting by Gilbert et al. [73]. This study enrolled 40 subjects aged 7-17 years. The preliminary data showed a statistically significant reduction of YGTSS scores at both 2 and 4 weeks, with mild-to-moderate side effects, but no weight gain, medication-induced side effects, EKG or laboratory changes. This study has not been submitted for publication at this point in time. 


\subsection{Complementary and Alternative Agents}

\subsubsection{Ningdong Granule}

Ningdong granule (NDG) is a formulation of four different plant species (Uncaria rhynchophylla (Miq.) Jacks, Gastrodia elata Blume, Ligusticum chuanxiong Hort, Glycyrrhiza uralensis), three animal products (Buthus martensii, Scolopendra subspinipes mutilans, Haliotis diversicolor), and dried human placenta [74]. NDG is thought to modulate dopamine content and dopamine D2 receptor content in the striatum. This was demonstrated by Zhang and Li by using two rat models in which concentrations of dopamine in the striatum were pharmacologically altered by using apomorphine (Apo) to increase the dopamine concentration in the rat striatum and 3,3'-iminodipropionitrile (IDPN) to decrease the dopamine concentration in the rat striatum. By using high-performance liquid chromatography, they demonstrated that alterations in dopamine content in the striatum was corrected in both rat models after administration of NDG, while no changes were seen with administration of haloperidol. There have been two RCT to evaluate the efficacy of NDG in treating tics. The first one was done in 2009 and compared haloperidol plus NDG to haloperidol alone in children with TS. At the end of their 24-week trial, they observed mean difference between the two groups in their YGTSS score of 4.35 points with a $95 \% \mathrm{CI}, p=0.004[75,76]$. The second one, a 2010 RCT conducted by Zhao et al., compared NDG with placebo over an 8-week period in children with TS between the ages of 7 and 18 years. After 8 weeks of treatment with NDG, subjects exhibited a $41.39 \%$ reduction in the YGTSS global score from baseline, while the placebo group showed a $10.79 \%$ reduction in YGTSS global score. Regarding side effects, two subjects reported loss of appetite and one experienced constipation in the NDG group, $p<0.001$ [77].

\subsubsection{5-Ling Granule}

5-Ling granule (5-LGr) is a patented polyherbal product with 11 herbal materials (Radix Paeoniae Alba, Rhizoma Gastrodiae, Fructus Tribuli, Ramulus Uncariae cum Uncis, Lucid Ganoderma, Caulis Polygoni Multiflori, Semen Ziziphi Spinosae, Fructus Schisandrae Chinensis, Fructus Gardeniae, Rhizoma Arisaematis cum bile, Radix Scutellariae) [78]. Zheng et al. performed a double-blind RCT in 2016 comparing the efficacy and safety of 5-LGr with placebo and tiapride. This multisite trial was conducted from January 2008 to November 2010 and prospectively recruited patients from eight different hospitals in China. The patients were between 5-18 years old and had to have a diagnosis of TS for at least 1 year based on the fourth edition of the DSM
(DSM-IV). All of the patients enrolled in this 8-week trial showed improvement in their YGTSS. The global YGTSS showed an average score improvement for placebo (baseline: 50, week 2: 44.4, week 8: 31.5), tiapride (baseline: 51.4, week 2: 43.2, week 8: 21.2) and 5-LGr (baseline: 52.1, week 2: 44.2, week 8: 22.3). The most common adverse events were "tiredness, reduced appetite and upper respiratory tract infections", which were seen in $11.2 \%$ of placebo patients, $26 \%$ of tiapride patients, and $13.8 \%$ of 5-LGr patients [78].

\subsubsection{Omega-3 Fatty Acids}

Omega-3 fatty acids (O3FAs) are long-chain polyunsaturated fatty acids of 18-22 carbon atoms in chain length with the first double bond between the third and fourth carbon atoms (n-3). Docosahexaenoic acid (DHA: 22 carbon atoms and 6 double bonds) and eicosapentaenoic acid (EPA: 20 carbon atoms and 5 double bonds) are main forms of O3FA [79]. In 2012, Gabbay et al. conducted a 20-week, doubleblind trial comparing O3FA (DHA:EPA capsules at a ratio of 2:1) with placebo in children with TS assessing the effects of O3FA on tic suppression by measuring changes in YGTSS tic, global and impairment scores. Their subjects had to fulfill the DSM-IV, Text Revision criteria for TD and have a minimum YGTSS of 20. Patients with any other medical or psychiatric disease were excluded and they did not exclude patients with TS on concomitant psychotropic medication. They enrolled 33 patients and had eight patients dropout (three O3FA group and five placebo group). At the end of the 20 -week period, there were no significant differences in response rates between O3FA and placebo on the YGTSS tic score (YGTSS tic score decrease of $5.2 \pm 7.3$ vs $3.6 \pm 5.6$ for O3FA and control group, respectively). They did, however, observe a decrease in the YGTSS global scores $(31.7+2.9$ vs $40.9+3.0$ ), and a trend in favor of O3FA on the YGTSS impairment scales $(16.9+2.1$ vs $23.0+2.2)$. O3FA are unlikely to have any role in tic reduction, but might play a role in helping with tic-related impairment and improvement in wellbeing [79].

\subsubsection{N-Acetylcysteine}

$N$-Acetylcysteine (NAC) is an amino acid supplement that has glutamate-modulating activity. NAC is converted to cystine, a substrate for the glutamate/cystine antiporter located on glial cells. The uptake of cystine by glia causes glial release of glutamate into the extra synaptic space, where it appears to stimulate inhibitory metabotropic glutamate receptors on glutamatergic nerve terminals, and thereby reduces the synaptic release of glutamate [80]. The glutamatergic system has been implicated in the pathogenesis of TS, with reduced glutamate levels found post mortem in the globus pallidus interna, globus pallidus externa, and 
substantia nigra pars reticulata in patients with TS compared with controls [6]. In 2016, a randomized, double-blind, placebo-controlled, add-on trial compared NAC with placebo in the treatment of tics in TS. Their primary goal was a reduction in the YGTSS in patients with TS who were on a stable medication regimen (no addition, discontinuation, or dosing change in medications that have potential effects on the central nervous system (such as antidepressants, naltrexone, lithium, psychostimulants, anxiolytics, or antipsychotics) in the previous 4 weeks prior to trial initiation). They enrolled 31 patients and had two patients drop out, one in the treatment group and one in the placebo group. Patients were randomized at a $1: 1$ ratio to receive either NAC or placebo as an add-on treatment. At the end of their 12-week trial, they observed no benefit with the use of NAC as an addon treatment for children and adolescents with TS on any primary or secondary clinical measures [81].

\section{Agents that are Ineffective}

\subsection{Pramipexole}

Pramipexole is a dopamine agonist that acts on D2, D3, and D4 receptors. In 2012, a randomized, multicenter, placebocontrolled trial compared pramipexole with placebo for tics in TS. Their primary outcome was a change in the YGTSS tic score. They were able to recruit 63 patients and completed a 6-week trial. At the end of the trial, there were no significant differences in the adjusted mean change in the total tic score of the YGTSS for patients treated with pramipexole and placebo [82].

\subsection{Metoclopramide}

Metoclopramide is classified as a neuroleptic medication with poor efficacy as an antipsychotic agent [83]. It is commonly used as an antiemetic and is the most common cause of drug-induced dyskinesias. A 2005 RCT in 27 patients aged 7-18 years demonstrated a $39 \%$ reduction in the YGTSS in the metoclopramide group, compared with a $13 \%$ reduction in the YGTSS in the control group [84]. This study provided weak evidence for the use of this medication for tics, and given the experience and potential for tardive dyskinesia and parkinsonism, it is not recommended for the treatment of tics in TS [14].

\section{Conclusions}

The treatment of TS has been slow to evolve over the last almost 50 years, since the approval of haloperidol by the FDA in 1969. For the majority of that time period, a large proportion of the medications that underwent investigation for the treatment of TS had a salient feature in common, they are D2 receptor antagonists. These medications, while proven to be effective, have the potential for serious side effects, either due to their D2 receptor antagonism, or their modulation of serotonin receptors, in the case of the atypical antipsychotics. The side effect profile of these medications, as delineated above, have relegated most of these medications to third- or fourth-line agents in the treatment of TS, despite their proven efficacy.

Aripiprazole is the first FDA-approved medication for the treatment of TS that does not have significant D2 antagonist effects. It also has significantly lower risk of hyperprolactinemia and weight gain than many of the other newer atypical antipsychotics [26].

For many practitioners, the alpha- 2 agonists, clonidine and guanfacine, have become first-line pharmacologic treatment for TS given their favorable side-effect profile compared with the antipsychotics. This is in spite of the fact that the level of evidence for their effectiveness is less than some of the antipsychotics and they are not FDA approved for the treatment of TS. This practice is reinforced by the Canadian treatment guidelines for the treatment of TS [14], whereas the European guidelines indicate that risperidone should be the first choice for pharmacotherapy [11].

In recent years, there has been increased interest in nonneuroleptic, non-noradrenergic options to control tics. Topiramate, a broad-spectrum anticonvulsant, has promising data regarding efficacy, but more studies are needed to confirm that it is truly effective. Ecopipam, the D1 receptor antagonist, has promising preliminary data, including a placebo-controlled trial supporting its effectiveness, but peer-reviewed published manuscripts are not available at the present time to assess side effects of this novel agent.

There is great interest in the VMAT2 inhibitors, especially given the recent FDA approval of valbenazine, and the preliminary, open-label data for deutetrabenzine. The interest in these agents arises from both patients and practitioners looking for safe and effective treatment options for TS. With the significant cost of tetrabenazine and valbenazine treatment in the US market, these medications, if effective, may have little impact on a large scale due to their expense.

In the US, there is presently a ubiquitous desire for the use of cannabinoid medications for many neurologic and non-neurologic disorders. The public plea for pharmacologic options in this category of potential pharmacologic agents stems, in large part, from the fact that they are derived from a natural source-the Cannabis sativa plant. Many patients and families, in response to the numerous stories of medications being removed from the market due to emerging side effects, as well as a desire to take a more 
naturopathic path in the treatment of disease, are incredibly interested in 'natural' treatments for their health concerns. There are very promising data for the use of cannabinoids, specifically THC, for the treatment of TS, but the studies are at this point small in number. There is the additional issue in the US regarding the legal status of cannabis and cannabis-derived pharmaceuticals, with numerous states debating, drafting, and passing laws regarding the use of such agents for a variety of health conditions. Large, multicenter studies are needed to truly determine the effectiveness of these medications for TS. Perhaps such studies, if remarkably positive in treating TS, would help to shape and move the political argument in a new direction.

Although currently limited, there are many new pathways in development that may provide unique therapeutic choices. Unlike epilepsy, where there are numerous genetic etiologies identified for its cause, there are precious few genetic clues regarding the cause of TS. The first study that has shown any statistically significant genetic results at the population level was published earlier this year, and while the results are important, there were genetic abnormalities discovered in only $1 \%$ of patients with TS [85]. Deriving therapeutic pharmaceuticals from these genetic targets does not appear to be logical at this time.

\section{Compliance with Ethical Standards}

Funding The funding for this publication and paying the fee for this publication to be made open access is from internal research funding granted to Keith A. Coffman, M.D. from the Department of Pediatrics at Children's Mercy Hospital, Kansas City.

Conflict of interest Julio F. Quezada, MD, has no conflicts to report. Keith A. Coffman, MD, is the Co-Chair of the Tourette Association of America Medical Advisory Board. He has also received honoraria for lectures given on behalf of the Tourette Association of America, but the content of those lectures is original and not reviewed or edited by the Tourette Association of America. Dr. Coffman has been a site Primary Investigator for a multi-center, randomized, placebo-controlled crossover trial of ecopipam for the treatment of Tourette syndrome, sponsored by Psyadon Pharmaceuticals, Inc.

Open Access This article is distributed under the terms of the Creative Commons Attribution-NonCommercial 4.0 International License (http://creativecommons.org/licenses/by-nc/4.0/), which permits any noncommercial use, distribution, and reproduction in any medium, provided you give appropriate credit to the original author(s) and the source, provide a link to the Creative Commons license, and indicate if changes were made.

\section{References}

1. Knight T, Steeves T, Day L, Lowerison M, Jette N, Pringsheim T. Prevalence of tic disorders: a systematic review and meta-analysis. Pediatr Neurol. 2012;47(2):77-90. https://doi.org/10.1016/j. pediatrneurol.2012.05.002.

2. Cath DC, Hedderly T, Ludolph AG, Stern JS, Murphy T, Hartmann A, Czernecki V, Robertson MM, Martino D, Munchau A,
Rizzo R, ESSTS Guidelines Group. European clinical guidelines for Tourette syndrome and other tic disorders. Part I: assessment. Eur Child Adolesc Psychiatry. 2011;20(4):155-71.

3. Paszek J, Pollok B, Biermann-Ruben K, Müller-Vahl K, Roessner V, Thomalla G, Robertson MM, Orth M, Schnitzler A, Münchau A. Is it a tic?-Twenty seconds to make a diagnosis. Mov Disord. 2010;25(8):1106-8.

4. American Psychiatric Association. Neurodevelopmental disorders In: Diagnostic and statistical manual for mental disorders. 5th ed. American Psychiatric Publishing. https://doi.org/10.1176/ appi.books.9780890425596.dsm01. Accessed 6 Jul 2017.

5. Piacentini J, Woods DW, Scahill L, Wilhelm S, Peterson AL, Chang S, Ginsburg GS, Deckersbach T, Dziura J, Levi-Pearl S, Walkup JT. Behavior therapy for children with Tourette disorder: a randomized controlled trial. JAMA. 2010;303(19):1929-37.

6. Robertson MM, Eapen V, Singer HS, et al. Gilles de la Tourette syndrome. Nat Rev Dis Primers. 2017;2(3):16097.

7. Jankovic J. Therapeutic developments for tics and myoclonus. Mov Disord. 2015;30(11):1566-73.

8. Hollis C, Pennant M, Cuenca J, Glazebrook C, Kendall T, Whittington C, Stockton S, Larsson L, Bunton P, Dobson S, Groom M, Hedderly T, Heyman I, Jackson GM, Jackson S, Murphy T, Rickards H, Robertson M, Stern J. Clinical effectiveness and patient perspectives of different treatment strategies for tics in children and adolescents with Tourette syndrome: a systematic review and qualitative analysis. Health Technol Assess. 2016;20(4):1-450, vii-viii.

9. Roessner V, Schoenefeld K, Buse J, Bender S, Ehrlich S, Münchau A. Pharmacological treatment of tic disorders and Tourette syndrome. Neuropharmacology. 2013;68:143-9.

10. Martino D, Madhusudan N, Zis P, Cavanna AE. An introduction to the clinical phenomenology of Tourette syndrome. Int Rev Neurobiol. 2013;112:1-33.

11. Roessner V, Plessen KJ, Rothenberger A, Ludolph AG, Rizzo R, Skov L, Strand G, Stern JS, Termine C, Hoekstra PJ, ESSTS Guidelines Group. European clinical guidelines for Tourette syndrome and other tic disorders. Part II: pharmacological treatment. Eur Child Adolesc Psychiatry. 2011;20(4):173-96.

12. Tourette's Syndrome Study Group. Treatment of ADHD in children with tics: a randomized controlled trial. Neurology. 2002;58(4):527-36.

13. Du YS, Li HF, Vance A, Zhong YQ, Jiao FY, Wang HM, Wang MJ, Su LY, Yu DL, Ma SW, Wu JB. Randomized double-blind multicentre placebo-controlled clinical trial of the clonidine adhesive patch for the treatment of tic disorders. Aust NZ J Psychiatry. 2008;42(9):807-13.

14. Pringsheim T, Doja A, Gorman D, McKinlay D, Day L, Billinghurst L, Carroll A, Dion Y, Luscombe S, Steeves T, Sandor P. Canadian guidelines for the evidence-based treatment of tic disorders: pharmacotherapy. Can J Psychiatry. 2012;57(3):133-43.

15. Chappell PB, Riddle MA, Scahill L, Lynch KA, Schultz R, Arnsten A, Leckman JF, Cohen DJ. Guanfacine treatment of comorbid attention-deficit hyperactivity disorder and Tourette's syndrome: preliminary clinical experience. J Am Acad Child Adolesc Psychiatry. 1995;34(9):1140-6.

16. Boon-yasidhi V, Kim YS, Scahill L. An open-label, prospective study of guanfacine in children with ADHD and tic disorders. J Med Assoc Thai. 2005;88(Suppl 8):S156-62.

17. Scahill L, Chappell PB, Kim YS, Schultz RT, Katsovich L, Shepherd E, Arnsten AF, Cohen DJ, Leckman JF. A placebocontrolled study of guanfacine in the treatment of children with tic disorders and attention deficit hyperactivity disorder. Am J Psychiatry. 2001;158(7):1067-74.

18. Cummings DD, Singer HS, Krieger M, Miller TL, Mahone EM. Neuropsychiatric effects of guanfacine in children with mild 
Tourette syndrome: a pilot study. Clin Neuropharmacol. 2002;25(6):325-32.

19. Murphy TK, Fernandez TV, Coffey BJ, Rahman O, Gavaletz A, Hanks CE, Tillberg CS, Gomez LI, Sukhodolsky DG, Katsovich L, Scahill L. Extended-release guanfacine does not show a large effect on tic severity in children with chronic tic disorders. J Child Adolesc Psychopharmacol. 2017;27(9):762-70.

20. Awaad Y. Tics in Tourette syndrome: new treatment options. J Child Neurol. 1999;14(5):316-9.

21. Singer HS, Wendlandt J, Krieger M, Giuliano J. Baclofen treatment in Tourette syndrome: a double-blind, placebo-controlled, crossover trial. Neurology. 2001;56(5):599-604.

22. Jankovic J, Jimenez-Shahed J, Brown LW. A randomised, double-blind, placebo-controlled study of topiramate in the treatment of Tourette syndrome. J Neurol Neurosurg Psychiatry. 2010;81:70-3.

23. Highlights in prescribing information for Botox. https://www. accessdata.fda.gov/drugsatfda_docs/label/2011/103000s5232lbl. pdf, Accessed 16 Jul 2017.

24. Marras C, Andrews D, Sime E, Lang AE. Botulinum toxin for simple motor tics: a randomized, double-blind, controlled clinical trial. Neurology. 2001;56:605-10.

25. Huys D, Hardenacke K, Poppe P, Bartsch C, Baskin B, Kuhn J. Update on the role of antipsychotics in the treatment of Tourette syndrome. Neuropsychiatr Dis Treat. 2012;8:95-104.

26. Budman CL. The role of atypical antipsychotics for treatment of Tourette's syndrome: an overview. Drugs. 2014;74(11):1177-93.

27. Pringsheim T, Marras C. Pimozide for tics in Tourette's syndrome. Cochrane Database Syst Rev. 2009;15(2):CD006996.

28. Gulisano M, Calì PV, Cavanna AE, Eddy C, Rickards H, Rizzo R. Cardiovascular safety of aripiprazole and pimozide in young patients with Tourette syndrome. Neurol Sci. 2011;32(6):1213-7.

29. Sallee FR, Nesbitt L, Jackson C, Sine L, Sethuraman G. Relative efficacy of haloperidol and pimozide in children and adolescents with Tourette's disorder. Am J Psychiatry. 1997;154(8):1057-62.

30. Shapiro AK, Shapiro E, Fulop G. Pimozide treatment of tic and Tourette disorders. Pediatrics. 1987;79(6):1032-9.

31. Rickards H, Hartley N, Robertson MM. Seignot's paper on the treatment of Tourette's syndrome with haloperidol. Hist Psychiatry. 1997;8(31 Pt 3):433-6.

32. Shapiro AK, Shapiro E. Treatment of Gilles De La Tourette's syndrome with haloperidol. $\mathrm{Br} \quad \mathrm{J}$ Psychiatry. 1968;114(508):345-50.

33. Shapiro E, Shapiro AK, Fulop G, Hubbard M, Mandeli J, Nordlie J, Phillips RA. Controlled study of haloperidol, pimozide, and placebo for the treatment of Gilles De La Tourette's syndrome. Arch Gen Psychiatry. 1989;46(8):722-30.

34. Ross MS, Moldofsky H. A Comparison of pimozide and haloperidol in the treatment of Gilles De La Tourette's syndrome. Am J Psychiatry. 1978;135(5):585-7.

35. Sandor P, Musisi S, Moldofsky H, Lang A. Tourette syndrome: a follow up study. J Clin Psychopharmacol. 1990;10(3):197-9.

36. Wijemanne S, Wu LJ, Jankovic J. Long-term efficacy and safety of fluphenazine in patients with Tourette syndrome. Mov Disord. 2014;29(1):126-30.

37. Borison RL, Ang L, Hamilton WJ, Diamond BI, Davis JM. Treatment approaches in Gilles de la Tourette syndrome. Brain Res Bull. 1983;11(2):205-8.

38. Rickards H, Cavanna AE, Worrall R. Treatment practices in Tourette syndrome: the European perspective. Eur J Paediatr Neurol. 2012;16(4):361-4.

39. Yoo HK, Joung YS, Lee JS, Song DH, Lee YS, Kim JW, Kim BN, Cho SC. A multicenter, randomized, double-blind, placebocontrolled study of aripiprazole in children and adolescents with Tourette's disorder. J Clin Psychiatry. 2013;74:e772-80.
40. Sallee F, Kohegyi E, Zhao J, McQuade R, Cox K, Sanchez R, van Beek A, Nyilas M, Carson W, Kurlan R. Randomized, doubleblind, placebo-controlled trial demonstrates the efficacy and safety of oral aripiprazole for the treatment of Tourette's disorder in children and adolescents. J Child Adolesc Psychopharmacol. 2017. https://doi.org/10.1089/cap.2016.0026.

41. Highlights of prescribing information for aripiprazole. https:// www.accessdata.fda.gov/drugsatfda_docs/label/2014/ 021436s038,021713s030,021729s022,021866s023lbl.pdf. Accessed 6 Jul 2017.

42. Bruggeman R, van der Linden C, Buitelaar C, Jan K, Gericke G, Hawkridge S, Temlett J. Risperidone versus pimozide in Tourette's disorder: a comparative double-blind parallel-group study. J Clin Psychiatry. 2001;62:50-6.

43. Gilbert D, Batterson J, Sethuramamn G, Sallee F. Tic reduction with risperidone versus pimozide in a randomized double-blind cross-over trial. J Am Acad Child Adolesc Psychiatry. 2004;43:206-14.

44. Dion Y, Annable L, Sandor P, Couinard G. Risperidone in the treatment of Tourette syndrome: a double-blind, placebo-controlled trial. J Clin Psychopharmacol. 2002;22:31-9.

45. Gaffney G, Perry P, Lund B, Bever-Stille K, Arndt S, Kuperman $\mathrm{S}$. Risperidone versus clonidine in the treatment of children and adolescents with Tourette's disorder. J Am Acad Child Adolesc Psychiatry. 2002;41:330-6.

46. Scahill L, Leckman L, Schultz R, et al. A placebo-controlled trial of risperidone in Tourette syndrome. Neurology. 2003;60:1130-5.

47. Pringsheim T, Lam D, Ching H, et al. Metabolic and neurological complications of second generation antipsychotic use in children: a systematic review and meta-analysis of randomized controlled trials. Drug Saf. 2011;34(8):651-68.

48. Stamenkovic M, Schindler SD, Aschauer HN, et al. Effective open-label treatment of tourette's disorder with olanzapine. Int Clin Psychopharmacol. 2000;15(1):23-8.

49. Onofrj M, Paci C, D’Andreamatteo G, et al. Olanzapine in severe Gilles de la Tourette syndrome: a 52-week double-blind crossover study vs low-dose pimozide. J Neurol. 2000;247(6):443-6.

50. Budman CL, Gayer A, Lesser M, et al. An open-label study of the treatment efficacy of olanzapine for Tourette's disorder. J Clin Psychiatry. 2001;62(4):290-4.

51. Stephens RJ, Bassel C, Sandor P. Olanzapine in the treatment of aggression and tics in children with Tourette's syndrome-a pilot study. J Child Adolesc Psychopharmacol. 2004;14(2):255-66.

52. McCracken JT, Suddath R, Chang S, et al. Effectiveness and tolerability of open label olanzapine in children and adolescents with Tourette syndrome. J Child Adolesc Psychopharmacol. 2008;18(5):501-8.

53. Sallee FR, Kurlan R, Goetz CG, Singer H, Scahill L, Law G, Dittman VM, Chappell PB. Ziprasidone treatment of children and adolescents with Tourette's syndrome: a pilot study. J Am Acad Child Adolesc Psychiatry. 2000;39(3):292-9.

54. Sallee FR, Miceli JJ, Tensfeldt T, Robarge L, Wilner K, Patel NC. Single-dose pharmacokinetics and safety of ziprasidone in children and adolescents. J Am Acad Child Adolesc Psychiatry. 2006;45(6):720-8.

55. de Jonge JL, Cath DC, van Balkom AJ. Quetiapine in patients with Tourette's disorder. J Clin Psychiatry. 2007;68(7):1148-50.

56. Mukaddes NM, Abali O. Quetiapine treatment of children and adolescents with Tourette's disorder. J Child Adolesc Psychopharmacol. 2003;13(3):295-9.

57. Eggers C, Rothenberger A, Berghaus U. Clinical and neurobiological findings in children suffering from tic disease following treatment with tiapride. Eur Arch Psychiatry Neurol Sci. 1988;237(4):223-9. 
58. Ho CS, Chen HJ, Chiu NC, Shen EY, Lue HC. Short-term sulpiride treatment of children and adolescents with Tourette syndrome or chronic tic disorder. $\mathrm{J}$ Formos Med Assoc. 2009;108(10):788-93.

59. Chen JJ, Ondo WG, Dashtipour K, Swope DM. Tetrabenazine for the treatment of hyperkinetic movement disorders: a review of the literature. Clin Ther. 2012;34:1487-504.

60. Jankovic J, Glaze DG, Frost JD Jr. Effect of tetrabenazine on tics and sleep of Gilles de la Tourette's syndrome. Neurology. 1984;34:688-92.

61. Jankovic J, Jimenez-Shahed J, Budman C, Coffey B, Murphy T, Shprecher D, Stamler D. Deutetrabenazine in tics associated with Tourette syndrome. Tremor Other Hyperkinet Mov (NY). 2016;6:422 (eCollection 2016).

62. Austedo medication package insert. https://www.accessdata.fda. gov/drugsatfda_docs/label/2017/209885lbl.pdf. Accessed 22 Oct 2017.

63. Kim ES. Valbenazine: first global approval. Drugs. 2017;77:1123-9.

64. Müller-Vahl KR, Schneider U, Koblenz A, Jöbges M, Kolbe H, Daldrup T, Emrich HM. Treatment of Tourette's syndrome with delta 9-tetrahydrocannabinol (THC): a randomized crossover trial. Pharmacopsychiatry. 2002;35:57-61.

65. Müller-Vahl KR, Schneider U, Prevedel H, Theloe K, Kolbe H, Daldrup T, Emrich HM. Delta 9-tetrahydrocannabinol (THC) is effective in the treatment of tics in Tourette syndrome: a 6-week randomized trial. J Clin Psychiatry. 2003;64:459-65.

66. Curtis A, Clarke CE, Rickards HE. Cannabinoids for Tourette's syndrome. Cochrane Database Syst Rev. 2009;4:CD006565.

67. Goetz CG. Clonidine and clonazepam in Tourette syndrome. Adv Neurol. 1992;58:245-51.

68. Drtilkova I, Balastikova B, Lemanova H. Clonazepam, clonidine, and tiapride in children with tic disorder. Homeostasis. 1996;5:216

69. Merikangas JR, Merikangas KR, Kopp U, Hanin I. Blood choline and response to clonazepam and haloperidol in Tourette's syndrome. Acta Psychiatr Scand. 1985;72(4):395-9.

70. Comings DE, Gursey BT, Avelino E, Kopp U, Hanin I. Red blood cell choline in Tourette syndrome. Adv Neurol. 1982;35:255-8.

71. Frederiks JA. Facial tics in children: the therapeutic effect of lowdosage diazepam. Br J Clin Pract. 1970;24(1):17-20.

72. Gilbert DL, Budman CL, Singer HS, Kurlan R, Chipkin RE. A D1 receptor antagonist, ecopipam, for treatment of tics in Tourette syndrome. Clin Neuropharmacol. 2014;37(1):26-30.

73. Gilbert D, Murphy T, Jankovic J, Budman C, Black K, Kurlan R, Coffman K, McCracken J, Juncos J, Grant J, Chipkin R. A randomized, double-blind, placebo-controlled study of the D1 receptor antagonist ecopipam for children and adolescents with Tourette syndrome [abstract]. Mov Disord. 2017;32(suppl 2). http://www.mdsabstracts.org/abstract/a-randomized-double-blindplacebo-controlled-study-of-the-d1-receptor-antagonist-ecopipamfor-children-and-adolescents-with-tourette-syndrome/. Accessed 3 Oct 2017.

74. Zhang F, Li A. Dual ameliorative effects of Ningdong granule on dopamine in rat models of Tourette's syndrome. Sci Rep. 2015;5:7731. https://doi.org/10.1038/srep07731.
75. Li AY, Cong S, Lu H, Li JJ, Zhao L. Clinical observation on treatment of Tourette syndrome by integrative medicine. Chin J Integr Med. 2009;15(4):261-5.

76. Kim YH, Son CG, Ku BC, Lee HW, Lim HS, Lee MS. Herbal medicines for treating tic disorders: a systematic review of randomised controlled trials. Chin Med. 2014;9(1):6.

77. Zhao L, Li AY, Lv H, Liu FY, Qi FH. Traditional Chinese medicine Ningdong granule: the beneficial effects in Tourette's disorder. J Int Med Res. 2010;38(1):169-75.

78. Zheng Y, Zhang Z-J, Han X-M, Ding Y, Chen Y-Y, Wang X-F, Wei X-W, Wang M-J, Cheng Y, Nie Z-H, Zhao M, Zheng X-X. A proprietary herbal medicine (5-Ling Granule) for Tourette syndrome: a randomized controlled trial. J Child Psychol Psychiatr. 2016;57:74-83.

79. Gabbay V, Babb JS, Klein RG, et al. A double-blind, placebocontrolled trial of omega-3 fatty acids in Tourette's disorder. Pediatrics. 2012;129(6):e1493-500.

80. Moran MM, McFarland K, Melendez RI, Kalivas PW, Seamans JK. Cystine/glutamate exchange regulates metabotropic glutamate receptor presynaptic inhibition of excitatory transmission and vulnerability to cocaine seeking. $J$ Neurosci. 2005;25:6389-93.

81. Bloch MH, Panza KE, Yaffa A, Alvarenga PG, Jakubovski E, Mulqueen JM, Landeros-Weisenberger A, Leckman JF. NAcetylcysteine in the treatment of pediatric Tourette syndrome: randomized, double-blind, placebo-controlled add-on trial. J Child Adolesc Psychopharmacol. 2016;26(4):327-34.

82. Kurlan R, Crespi G, Coffey B, Mueller-Vahl K, Koval S, Wunderlich G, on behalf of the Pramipexole for TS Trial Investigators. A multicenter randomized placebo-controlled clinical trial of pramipexole for Tourette's syndrome. Mov Disord. 2012;27:775-8.

83. Acosta MT, Castellanos FX. Use of the 'Inverse Neuroleptic' metoclopramide in Tourette syndrome: an open case series. J Child Adolesc Psychopharmacol. 2004;14(1):123-8.

84. Nicolson R, Craven-Thuss B, Smith J, McKinlay BD, Castellanos FX. A randomized, double-blind, placebo-controlled trial of metoclopramide for the treatment of Tourette's disorder. J Am Acad Child Adolesc Psychiatry. 2005;44(7):640-6.

85. Huang AY, Yu D, Davis LK, Sul JH, Tsetsos F, Ramensky V, Zelaya I, Ramos EM, Osiecki L, Chen JA, McGrath LM, Illmann C, Sandor P, Barr CL, Grados M, Singer HS, Nöthen MM, Hebebrand J, King RA, Dion Y, Rouleau G, Budman CL, Depienne C, Worbe Y, Hartmann A, Müller-Vahl KR, Stuhrmann M, Aschauer H, Stamenkovic M, Schloegelhofer M, Konstantinidis A, Lyon GJ, McMahon WM, Barta C, Tarnok Z, Nagy P, Batterson JR, Rizzo R, Cath DC, Wolanczyk T, Berlin C, Malaty IA, Okun MS, Woods DW, Rees E, Pato CN, Pato MT, Knowles JA, Posthuma D, Pauls DL, Cox NJ, Neale BM, Freimer NB, Paschou P, Mathews CA, Scharf JM, Coppola G, Tourette Syndrome Association International Consortium for Genetics (TSAICG), Gilles de la Tourette Syndrome GWAS Replication Initiative (GGRI). Rare copy number variants in NRXN1 and CNTN6 increase risk for Tourette syndrome. Neuron. 2017;94:1101-11. 